\title{
LDH-GO composites as catalysts for the oxidative removal of indigo carmine dye from wastewater
}

https://doi.org/10.21698/rjeec.2020.201

\author{
Proceedings Paper
}

\section{ALEXANDRA-ELISABETA STAMATE ${ }^{1}$, RODICA ZAVOIANU $^{1 *}$, OCTAVIAN DUMITRU PAVEL $^{1}$, ANCA CRUCEANU ${ }^{1}$, MIHAI COSMIN COROBEA ${ }^{2}$, MARIANA OSIAC $^{3}$, NICOLETA CIOATERA ${ }^{3}$}

\author{
${ }^{1}$ University of Bucharest, Faculty of Chemistry, Department of Organic Chemistry, Biochemistry \& Catalysis, 4-12 \\ Blvd. Regina Elisabeta, Bucharest, 030018, phone: +40746171699, Romania \\ ${ }^{2}$ INCDCP-ICECHIM, Polymer Department, 202 Splaiul Independentei, Bucharest, 060021, Romania \\ ${ }^{3}$ University of Craiova, INCESA, 97 Blvd. Decebal, 200440, Craiova, Romania \\ *Corresponding author (e-mail): rodica.zavoianu@chimie.unibuc.ro
}

\begin{abstract}
Herein, we present the results of our researches focused on obtaining composites with enhanced affinity for indigo carmine (IC) by combining two different $2 D$ materials e.g. graphene oxide (GO) and a Cerium modified layered double hydroxide ( $L D H)$, which could act as catalysts for the oxidative removal of IC, both under ultrasonic irradiation and under conventional stirring, using $\mathrm{H}_{2} \mathrm{O}_{2}$ as oxidation agent. Three $\mathrm{Mg}_{3} \mathrm{Al}_{0.75} \mathrm{Ce}_{0.25} \mathrm{LDH}-\mathrm{GO}$ composites bearing different concentrations of $\mathrm{GO}$ in the range of 5-15 wt.\% abbreviated as HT3Ce-xGO where $x$ stands for the concentration of $G O(x=5,10,15 \% \mathrm{wt}$. GO) have been prepared and characterized by XRD, SEM, Raman, and DRIFT spectroscopy. The XRD patterns of HT3Ce$x \mathrm{GO}$ solids have revealed the formation of nanocomposites with fine particles of $\mathrm{CeO}_{2}$ (Scherrer dimensions around $3 \mathrm{~nm}$ ) embedded in the $2 \mathrm{D}$ layered structure of $\mathrm{LDH}-\mathrm{GO}$. CeO $\mathrm{O}_{2}$ phase was favored by the increase in GO content for all investigated composites. The size decrease of the solid particles with the increase of GO content was proved both by SEM and DRIFT analyses. Raman spectra proved the incorporation of GO in all composites. The results of the catalytic tests showed, without any doubt the activation effect of the ultrasonic irradiation which allowed doubling the dye removal percentage (DR\%) in the first 30 minutes of reaction time. For the most active catalyst, HT3Ce-15GO, the COD after 30 minutes reaction time under ultrasonic irradiation was $221 \mathrm{mg} \mathrm{O}_{2} / \mathrm{L}$, while TOC was $93 \mathrm{mg} \mathrm{C} / \mathrm{L}$ marking a decay of $61.6 \%$ for COD and $46.2 \%$ for TOC.
\end{abstract}

Keywords: advanced oxidation, Ce-modified hydrotalcite, graphene oxide, indigo carmine, layered double hydroxide

\section{INTRODUCTION}

Water contamination with persistent dyes discharged from the textile, pharmaceutical, and food industries is a stringent issue for environmental protection since it affects the water transparency and gas solubility in water hindering as well the growth of aquatic species and the photosynthesis process. Acute or chronic effects on the health of water living organisms were also noticed depending on the dye pollutant concentration and the exposure time. Due to the organic nature of dye pollutants, dye contaminated wastewaters have higher values of the chemical oxygen demand (COD) and the total organic carbon content (TOC). Usually, these dyes cannot be degraded or biodegraded in classical wastewater treatment [1]. Moreover, the partial degradation products of the organic dyes can be highly carcinogenic or mutagenic compounds, which can have even more negative effects on the organisms than the dye itself. Hence, advanced oxidation processes (AOP) are required for their mineralization [2, 3]. Lately, among the AOP that have aroused, there is a growing interest for those based on sono-catalysis which are considered cheaper than the photo-catalytic ones [4-6]. Disodium (2E)-3-oxo-2-(3-oxo-5-sulfonato-2,3-dihydro1H-indol-2-ylidene)-2,3-dihydro-1H-indole-5sulfonate also called indigo carmine (IC) is an indigoid water-soluble dye (Fig. 1) authorized as synthetic food color for a wide range of food categories with a maximum permitted levels between 50 and $500 \mathrm{mg} / \mathrm{kg}$ food [7]. It may become toxic leading to atrioventricular block and polymorphous supraventricular 
bigeminy as well as potentially carcinogenic weight/day [7-9]. when exceeding doses of $500 \mathrm{mg} / \mathrm{kg}$ body

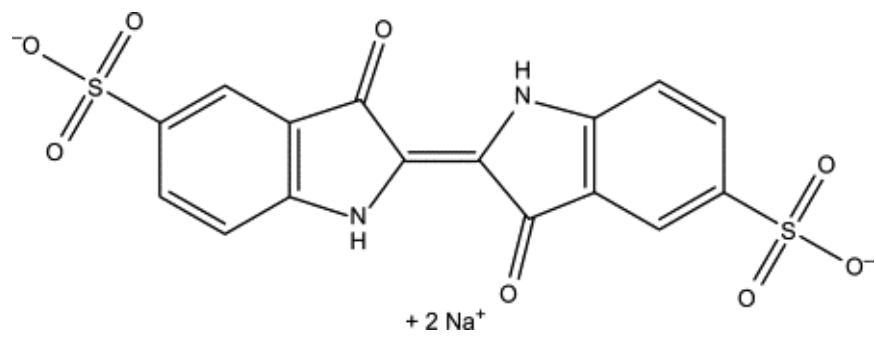

Fig.1. The chemical structure of indigo carmine (IC)

Indigo carmine mineralization by photocatalytic AOP using $\mathrm{TiO}_{2}$ as the photocatalyst was found to be difficult since there was no noticeable loss of the TOC value and release of inorganic ions even if the water coloration disappeared [10]. Recently, it has been proved that $\mathrm{MnO}_{2}$ could efficiently remove indigo carmine from polluted water by a combined process using both photo and ultrasonic activation [11]. It has been considered that the catalytic activity of $\mathrm{MnO}_{2}$ was due to its high affinity for $\mathrm{O}_{2}$ and its efficient adsorption of the dye. The degradation of indigo carmine with this catalyst was more efficient with peroxydisulfate $\left(\mathrm{S}_{2} \mathrm{O}_{8}{ }^{-}\right)$as an oxidation agent rather than with hydrogen peroxide which was found to inhibit the process. However, the development of AOP using greener oxidants such as hydrogen peroxide would be of higher interest. Another important challenge would be the enhancement of the solid affinity for the organic substrate. In 2019, it was reported that mixed oxides obtained by thermal decomposition of $\mathrm{Zn}_{\mathrm{x}} \mathrm{Al}$ layered double hydroxides $(\mathrm{x}=2-4)$ exhibit good adsorption capacities for both indigo carmine and methylene blue dyes [12]. Layered double hydroxides (LDH) also called hydrotalcite (HT)-like compounds are anionic clays having the general formula $\left[\mathrm{M}^{\mathrm{II}}{ }_{1-\mathrm{x}} \mathrm{M}^{\mathrm{III}}{ }_{\mathrm{x}}(\mathrm{OH})_{2}\right]^{\mathrm{x}+}\left[\mathrm{A}^{\mathrm{n}-}\right.$ ]$_{\mathrm{X} / \mathrm{n}} \bullet \mathrm{zH} \mathrm{H}_{2} \mathrm{O}$, where $\mathrm{M}^{\mathrm{II}}$ is a bivalent metal cation, $\mathrm{M}^{\mathrm{III}}$ is a trivalent metal cation, $\mathrm{A}^{\mathrm{n}-}$ is a charge compensation anion which may be either inorganic or organic, $x$ has a value between 0.2 and 0.4. LDH solids are formed of positively charged brucite-type layers containing the cations hexacoordinated with hydroxyl groups. Between two brucite-type layers, there is a space called the interlayer region containing the compensation anions and water molecules. These solids are renowned by their anion exchangeability and by their so-called "memory effect" which consist in the recovery of the layered structure when a mixed oxide obtained by the thermal decomposition of an $\mathrm{LDH}$ precursor (at temperatures lower than $650^{\circ} \mathrm{C}$ ) is immersed in an aqueous solution containing different anions [13]. Hence, the affinity of $\mathrm{Zn}_{\mathrm{x}} \mathrm{Al}$ mixed oxides for the anionic dye indigo carmine was considered to be a consequence of the memory effect exhibited by their LDH precursors. Ten years ago, graphene oxide (GO) is a good catalyst for facilitating oxidation and hydration reactions [14]. Since then, the researches on the catalytic activity of GO were continuously extended and quite recently the catalytic activity of $\mathrm{GO}-\mathrm{MnO}_{2}$ nanocomposites for azo dyes (reactive black 5) degradation with hydrogen peroxide was discovered and explained by the synergetic effect of the GO which favors the adsorption of the organic substrate and the $\mathrm{MnO}_{2}$ which promotes the oxidation [15]. However, the limitation of this process is the low $\mathrm{pH}$ value (e.g. $\mathrm{pH}=3$ ) necessary to reach high conversions. Based on this state of the art, our attention was drawn to the obtaining of new composites by combining two different 2D materials, GO and a Cerium modified LDH which could act as catalysts for the oxidative removal of indigo carmine using hydrogen peroxide as oxidant. Herein, we present the results of our researches on the synthesis, characterization, and catalytic activity of $\mathrm{Mg}_{3} \mathrm{Al}_{0.75} \mathrm{Ce}_{0.25} \mathrm{LDH}-\mathrm{GO}$ composites for the oxidation of indigo carmine with $\mathrm{H}_{2} \mathrm{O}_{2}$, both under ultrasonic irradiation and under conventional stirring. 


\section{MATERIALS AND METHODS}

The chemicals necessary for the synthesis of the LDH phase, e.g. magnesium nitrate hexahydrate $\mathrm{Mg}\left(\mathrm{NO}_{3}\right)_{2}$ x $6 \mathrm{H}_{2} \mathrm{O}$, aluminum nitrate nonahydrate $\mathrm{Al}\left(\mathrm{NO}_{3}\right)_{3} \times 9 \mathrm{H}_{2} \mathrm{O}$, cerium nitrate hexahydrate $\mathrm{Ce}\left(\mathrm{NO}_{3}\right)_{3} \times \mathrm{H}_{2} \mathrm{O}$, anhydrous sodium carbonate $\mathrm{Na}_{2} \mathrm{CO}_{3}$, and sodium hydroxide $\mathrm{NaOH}$ (pearls) were all of the chemical purity grades and were purchased from Merck.

For the preparation of the GO phase, graphite powder 325 mesh from Aldrich, sodium nitrate $\mathrm{NaNO}_{3}$ and potassium permanganate $\mathrm{KMnO}_{4}$ (chemical purity from Merck), $\mathrm{H}_{2} \mathrm{SO}_{4}(98 \%)$ and hydrochloric acid $\mathrm{HCl} 37 \%$ (from Merck) and hydrogen peroxide $\mathrm{H}_{2} \mathrm{O}_{2} \quad 30 \%$ (from ChimReactiv) were utilized.

Indigo carmine (IC) from Fluka AG was used for the preparation of the dye contaminated water.

All the aqueous solutions were obtained using distilled water with a conductivity of 2.5-5 $\mu \mathrm{S} / \mathrm{cm}$.

Three $\mathrm{Mg}_{3} \mathrm{Al}_{0.75} \mathrm{Ce}_{0.25}$ LDH-GO composites bearing different concentrations of $\mathrm{GO}$ in the range of 5-15 wt.\% abbreviated as HT3Ce-xGO where $\mathrm{x}$ stands for the concentration of $\mathrm{GO}$ $(x=5,10,15 \%$ wt. GO) have been prepared by the co-precipitation of the $\mathrm{LDH}$ phase in the presence of GO at constant $\mathrm{pH} 10$. First, the GO was prepared using the well-known Hummers method [16] by contacting $10 \mathrm{~g}$ of graphite powder with $5 \mathrm{~g} \mathrm{NaNO}_{3}, 230 \mathrm{~mL} \mathrm{H}_{2} \mathrm{SO}_{4}(98 \%)$, and $30 \mathrm{~g} \mathrm{KMnO}_{4}$ at $5-30{ }^{\circ} \mathrm{C}$ for $1 \mathrm{~h}$, followed by the addition of $710 \mathrm{~mL}$ distilled water and heating of the resulting mixture at $98-110^{\circ} \mathrm{C}$ for 15 minutes and then adding $50 \mathrm{~mL}$ of $\mathrm{H}_{2} \mathrm{O}_{2}$ $(30 \%)$ to reduce the remaining $\mathrm{Mn}^{+7}, \mathrm{Mn}^{+4}$ species to $\mathrm{Mn}^{+2}$ (as water-soluble manganese sulfate), thus enabling the formation of GO yellowish flakes. The solid phase is then separated by centrifugation, washed first with dilute $\mathrm{HCl}$ (obtained by mixing equal volumes of distilled water and $\mathrm{HCl} 37 \%$ ) and then with hot distilled water until the conductivity of the liquid in the centrifuge vials becomes lower than $100 \mu \mathrm{S} / \mathrm{cm}$. After reaching this point, all the content of the centrifuge vials was collected and diluted with distilled water in a $5 \mathrm{~L}$ volumetric flask. The concentration of GO in the suspension was determined using the gravimetric method, by weighing in Petri dishes
3 liquid samples of $100 \mathrm{~mL}$ before and after the evaporation of water under vacuum at $60^{\circ} \mathrm{C}$ for $24 \mathrm{~h}$. The amount of solid recovered from the 3 samples was $0.4001 \mathrm{~g}, 0.4005 \mathrm{~g}$, and $0.3998 \mathrm{~g}$ which gave an average value of the GO concentration in the suspension of $4 \mathrm{~g} / \mathrm{L}$.

For the preparation of the Ce-modified LDH compound by co-precipitation at constant $\mathrm{pH} 10$ under low supersaturation conditions, the method described for the obtaining of other rare-earth modified LDH [17] was adapted. An aqueous solution $\mathrm{A}$ having a concentration of $1.5 \mathrm{M}$ of cations $\mathrm{Mg}^{2+}, \mathrm{Al}^{3+}$, and $\mathrm{Ce}^{3+}$ while respecting the molar ratio $\mathrm{Mg}^{2+} / \mathrm{Al}^{3+} / \mathrm{Ce}^{3+}$ of $3 / 0.75 / 0.25$ ) and a solution $\mathrm{B}$ containing $\mathrm{NaOH}$ and $\mathrm{Na}_{2} \mathrm{CO}_{3}$ (1 $\mathrm{M}$ concentration of $\mathrm{Na}^{+}$ions, with a molar ratio $\mathrm{NaOH} / \mathrm{Na}_{2} \mathrm{CO}_{3}$ of 2.5/1) were prepared by dissolving the corresponding amounts of chemicals in distilled water. TIM854 Titration Manager from Radiometer analytical specialized in maintaining a constant $\mathrm{pH}$ value was utilized for the precipitation. The precipitation reactor filled with $100 \mathrm{~mL}$ distilled water was placed on the stirring plate of TIM854, the $\mathrm{pH}$ electrode was immersed in the reactor and the $\mathrm{pH}$ of the water was adjusted to 10 using $\mathrm{B}$ solution which was placed in the automatic burette of TIM854, then it was started the concomitant dropwise addition of solution A and solution B to achieve the precipitation at room temperature under vigorous stirring. Using this equipment the flow rate of solution $\mathrm{B}$ was automatically adjusted to maintain the constant $\mathrm{pH} 10$. After consuming all solution $\mathrm{A}$, the precipitation reactor was transferred on a heating stirring plate, a vertical condenser was mounted on its mouth and the gel was aged at $75^{\circ} \mathrm{C}$ for $18 \mathrm{~h}$. Afterward, the gel was filtered and washed with distilled water until the conductivity of the washing water decreased below $100 \mu \mathrm{S} / \mathrm{cm}$, then the solid cake was dried in an oven at $90^{\circ} \mathrm{C}$ for $24 \mathrm{~h}$ yielding $\mathrm{Mg}_{3} \mathrm{Al}_{0.75} \mathrm{Ce}_{0.25} \mathrm{LDH}$.

For the preparation of $\mathrm{Mg}_{3} \mathrm{Al}_{0.75} \mathrm{Ce}_{0.25} \mathrm{LDH}-\mathrm{GO}$ composites, the amounts of metal nitrates necessary to obtain $9.5,9$, and 8.5 grams of LDH phase respectively, were dissolved in an aqueous suspension of GO containing $0.5,1$, and 1.5 grams of $\mathrm{GO}$, and distilled water was added to reach the $1.5 \mathrm{M}$ concentration of cations $\left(\mathrm{Mg}^{2+}, \mathrm{Al}^{3+}\right.$, and $\left.\mathrm{Ce}^{3+}\right)$ as in the above- 
described solution A utilized for the obtaining of Ce-modified LDH. Solution B and all the other stages of the synthesis were identical to the above-described procedure.

The characterization of the solids included XRay diffraction of powders (XRD), diffuse reflectance infrared Fourier-transform spectroscopy (DRIFTS), Raman spectroscopy, $D_{\mathrm{hkl}}=\left(\mathrm{K} \lambda / \beta_{\mathrm{hkl}} \cos \theta_{\mathrm{hkl}}\right)$

where $\mathrm{K}$ is a geometric factor (e.g. 0.9), $\lambda$ is the wavelength of the incident X-ray, $\beta_{\mathrm{hkl}}$ is the width at half-intensity of the $h k l$ reflection, and $\theta_{\text {hkl }}$ is the Bragg angle of the same reflection.

DRIFTS spectra of the freshly prepared and spent solid samples were recorded with a Jasco FT/IR 4700 spectrometer having a PIKE accessory for diffuse reflectance. The spectra were collected in the spectral range 4000-400 $\mathrm{cm}^{-1}$, with a scanning speed of $128 \mathrm{scans} / \mathrm{min}$ and a resolution of $4 \mathrm{~cm}^{-1}$ using $\mathrm{KBr}$ as background.

A high-resolution confocal Raman microscope (Renishaw system, Renishaw UK Ltd) equipped with two laser lines $(514 \mathrm{~nm}$ and $785 \mathrm{~nm}$, respectively) and a Leica DM2500 microscope was utilized for recording the Raman spectra of the solid samples, in extended mode using the $514 \mathrm{~nm}$ laser line, monitoring the shifts in the Raman band position narrower than $0.5 \mathrm{~cm}^{-1}$, and measuring the Raman bands in the range $100-3100 \mathrm{~cm}^{-1}$.

SEM analysis of the samples was performed on Hitachi Ultrahigh Resolution Scanning Electron Microscope SU8010 with a semi-in-lens type objective lens and cold FE-gun with small energy spread.

\section{RESULTS AND DISCUSSION}

The diffraction pattern of $\mathrm{Mg}_{3} \mathrm{Al}_{0.75} \mathrm{Ce}_{0.25} \mathrm{LDH}$ in Fig. 2 shows besides the typical reflections $(003,006,009,012,015,018,110$, and 113) of a lamellar hydrotalcite-like structure $\left(\mathrm{Mg}_{3} \mathrm{Al}-\right.$ ICDD card no 00-054-1029), those characteristic to $\mathrm{CeO}_{2}$ cubic phase $(111,200$ and 220) with fluorite structure (ICDD card no 00-034-0394) and low-intensity lines of cerium hydroxycarbonate (marked with $*$ on Fig. 2) $\left(\mathrm{Ce}\left(\mathrm{CO}_{3}\right)_{2} \mathrm{O} . \mathrm{H}_{2} \mathrm{O}\right.$-ICDD card 00-044-0617). It seems that $\mathrm{Ce}^{3+}$ fails to enter in the brucite-type layer due to its larger ionic radius $(1.01 \AA)$ compared to those of $\mathrm{Mg}^{2+}(0.72 \AA)$ and $\mathrm{Al}^{3+}$ and scanning electron microscopy (SEM).

$\mathrm{XRD}$ patterns in the $2 \theta$ range $5-80^{\circ}$ were obtained with XRD 6000 Shimadzu, equipped with a lamp of $\mathrm{Cu}\left(\lambda_{\mathrm{CuK} \alpha}=1.5418 \AA, 40 \mathrm{kV}, 40\right.$ $\mathrm{mA}$ ) in continuous scanning mode with a step of $0.02 \% \mathrm{~min}$ and an acquisition time per step of 4 seconds. The dimensions of the crystallites were calculated using Scherrer's formula:

The catalytic oxidation of IC was performed in a batch system at room temperature using 1 wt.\% catalyst in simulated wastewater containing 420 ppm IC and $\mathrm{H}_{2} \mathrm{O}_{2}(5.5$ wt.\%) as an oxidation agent. The same composition of the reaction mixture was used in two types of catalytic tests: i) under stirring at $400 \mathrm{rot} / \mathrm{min}$ (abbreviated as ST) and ii) under ultrasonic irradiation of $37 \mathrm{kHz}$ (abbreviated as UST). To highlight the effect of the catalyst, blank tests were performed without adding the catalyst in the reaction mixture. The dye removal extent (DR \%) was determined using UV-Vis spectrometry by monitoring the variation of the absorption maximum at $\lambda=610 \mathrm{~nm}$ using double beam UV-Vis spectrometer Jasco 650.

The degradation of the organic compound was also assessed by determining the chemical oxygen demand (COD) and the total organic carbon (TOC) content in the treated wastewater. Both COD and TOC were determined using the Aqualytic AL800 spectrometer and the corresponding reagent kits COD Vario tube tests $0-1500 \mathrm{mg} / \mathrm{L}$ and $0-150 \mathrm{mg} / \mathrm{L}$ form Tintometer $\mathrm{GmbH}$, Division Aqualytic and TOC Cell test $(50-800 \mathrm{mg} / \mathrm{L})$ from Merck KgaA.

(0.535 ̊). Therefore, the LDH-modification with Ce leads mainly to an alteration of the structure explaining the ill crystallized HTphase observed in the XRD patterns of the dried $\mathrm{Mg}_{3} \mathrm{Al}_{0.75} \mathrm{Ce}_{0.25} \mathrm{LDH}$.

The XRD pattern of GO (ICDD card 00-0651528) shows the characteristic (001) diffraction line for layered hexagonal crystals which appears in the same region as the most intense line (003) of the LDH. The XRD patterns of all the composite materials HT3Ce-xGO had more intense and better-defined diffraction lines characteristic to the lamellar hydrotalcite-like 
structure than the neat $\mathrm{Mg}_{3} \mathrm{Al}_{0.75} \mathrm{Ce}_{0.25} \mathrm{LDH}$ or the neat GO. Besides, only the specific lines of $\mathrm{CeO}_{2}$ are noticed while those corresponding to the cerium hydroxycarbonate are missing. The formation of the $\mathrm{CeO}_{2}$ phase was favored by the increase of GO content in HT3Ce-xGO composites. These facts suggest that the precipitation of the $\mathrm{LDH}$ in the presence of GO suspension promotes the crystallization of the LDH phase along with the embedding of fine $\mathrm{CeO}_{2}$ particles having Scherrer dimensions around $3 \mathrm{~nm}$.

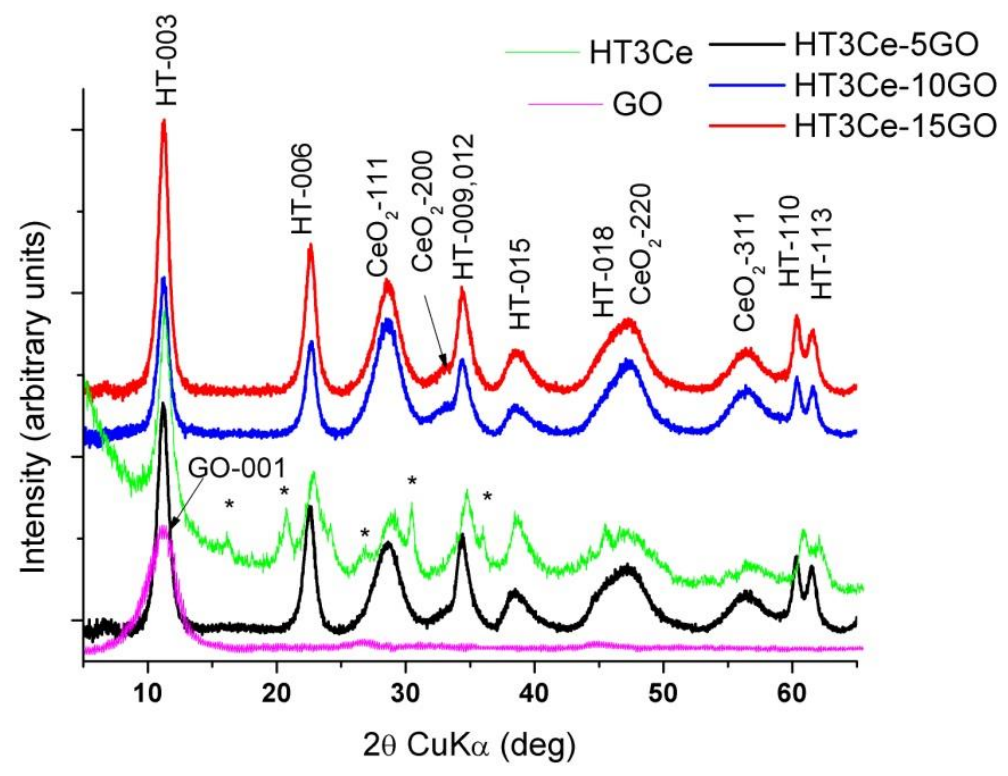

Fig. 2. XRD patterns of the solid samples

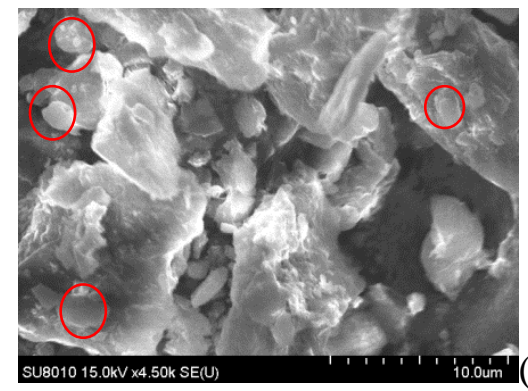

A) HT3Ce-5GO

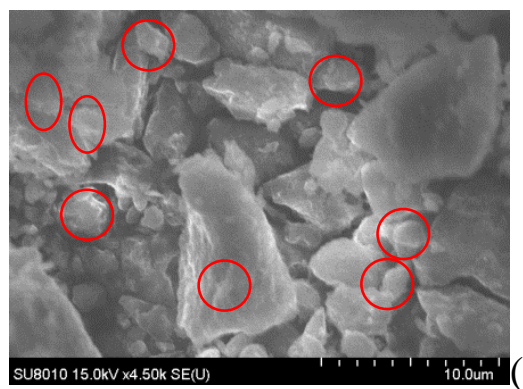

B) HT3Ce-10GO

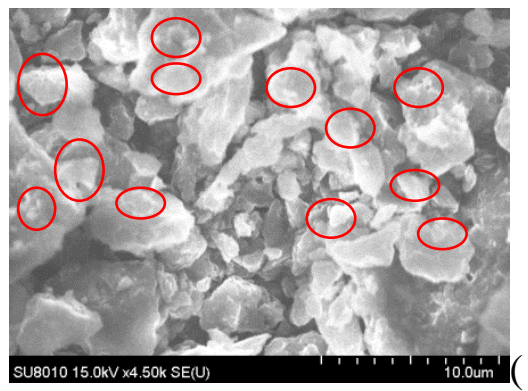

C) $\mathrm{HT} 3 \mathrm{Ce}-15 \mathrm{GO}$

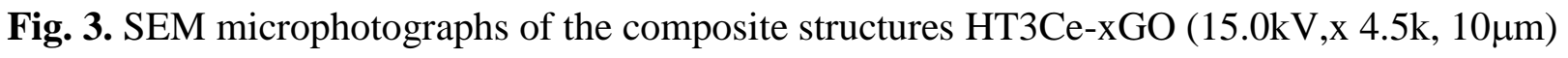

The composite structures, analyzed by SEM in powder form, showed for all the samples welldefined grains, with different sizes and surface morphology when closely inspected. As emphasized by XRD structural analysis, the grains composition contains a well-defined LDH structure decorated with a distinct $\mathrm{CeO}_{2}$ phase. In this context, $\mathrm{Ce}$ ions involvement should be noticed, since they could play a key role with the GO layers during the $\mathrm{LDH}$ synthesis. GO layers can offer plenty of sites, left non-oxidized during GO synthesis. Therefore the GO interaction during $\mathrm{LDH}$ synthesis should not be ignored, from both physical (nucleating) and chemical reason (interaction with $\mathrm{Ce}$ ions). Moreover, it was already reported that the ceria phase has an affinity for attachment onto GO [18]. The grain surface, revealed the transition from a relatively smooth surface towards a rougher polymorphic surface as the GO concentration increased. At high GO content, better accessibility towards the smaller elementary particles was observed. The elementary particles consist either in layered polymorphic particles with edges or in „ovoidal” composite particles (Fig. 3). The presence of ,ovoidal" particles on the surface of the grains (marked with red circles in Fig. 3) drastically increases with GO concentration. These results are in good agreement with XRD 
data which are suggesting a certain involvement of the GO in the composite HT3Ce-xGO phase arrangements. A possible explanation of the overall mechanism for the occurrence of the „ovoidal" composite particles and their positioning towards the surface could be related also to the complex role played by $\mathrm{Ce}$ ions. On one hand, they can influence the oxidantreductive balance and act on GO sites (not completely oxidized) and by another, they could induce a basic character in the $\mathrm{LDH}$ reaction loci, leading to a spherical association of the hexagonal LDH platelets [19].

The presence of GO in all the composites HT3Ce-xGO was clearly evidenced by Raman spectra of the samples which are displayed in Fig. 4. The spectrum of HT3Ce shows several bands characteristic to the LDH structure e.g. a broad Raman band at $137 \mathrm{~cm}^{-1}$ (assigned to the LDH lattice vibrations), a band at $548 \mathrm{~cm}^{-1}$ (symmetric stretching vibration of the hydrogen bonds formed between interlayer water and carbonate where the two hydrogen atoms of the $\mathrm{H}_{2} \mathrm{O}$ molecule are bridged to the two oxygen atoms of the carbonate anion) and another band related to the $v_{1}$ symmetric stretch of A1' symmetry of carbonate anion at $1069 \mathrm{~cm}^{-1}$ [20]. Besides these, there is also a band-specific to nanocrystalline $\mathrm{CeO}_{2}$ at $465 \mathrm{~cm}^{-1}$ and weak Raman shifts in the high-frequency region between 800 and $900 \mathrm{~cm}^{-1}$, specific to peroxide $\left(\mathrm{O}_{2}{ }^{2-}\right)$ stretching vibrations at the oxidized and defective ceria surfaces [21].

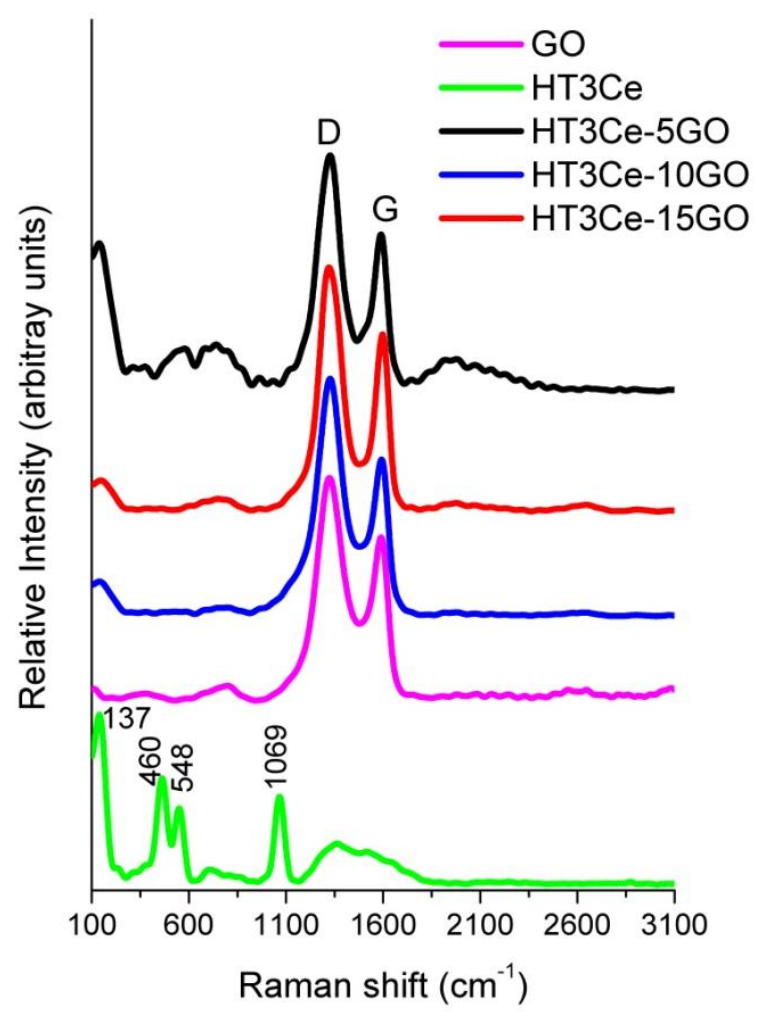

Fig. 4. Raman spectra of the investigated samples

The Raman spectrum of GO shows the D band which is the dominant $\mathrm{sp}^{2}$ Raman signature of disorder in nanocrystalline carbonic structures at $1321 \mathrm{~cm}^{-1}$ and the band $\mathrm{G}$ at $1586 \mathrm{~cm}^{-1}$ (characteristic to planar carbonic structures with $\mathrm{sp}^{2}$ hybridized $\mathrm{C}$ atoms) [22], while the ratio between the intensities of the two bands is $\mathrm{I}_{\mathrm{D}} / \mathrm{I}_{\mathrm{G}}=1.316$. Besides the band at $137 \mathrm{~cm}^{-1}$ characteristics to the LDH lattice vibrations, in the Raman spectra of the HT3Ce-xGO composites, the characteristic features of the GO component overlap the bands specific to the LDH component. Only the spectrum of HT3Ce$5 \mathrm{GO}$ shows deformed weak bands in the region 200-800 $\mathrm{cm}^{-1}$ which could be caused by the LDH component of the nanocomposite. In the spectra of all composites, the positions of the GO bands D and G are slightly shifted to 1326 and $1593 \mathrm{~cm}^{-1}$ respectively while the ratio $\mathrm{I}_{\mathrm{D}} / \mathrm{I}_{\mathrm{G}}$ increases with the GO content in the sample 
$(5 \%, 10 \% 15 \%)$ to $1.357,1.424$, and 1.473 respectively, indicating an increased disturbance of the GO layer.

DRIFT spectra presented in (Fig. 5a) showed that $\mathrm{GO}$ has the characteristic absorption peaks for $\mathrm{C}=\mathrm{O}$ carbonyl stretching at $1731 \mathrm{~cm}^{-1}, 1640$ $\mathrm{cm}^{-1}\left(\delta_{\mathrm{H} 2 \mathrm{O}}\right), 1427 \mathrm{~cm}^{-1}$ (Usim $\left.\mathrm{COO}^{-}\right), 1264 \mathrm{~cm}^{-1}(\mathrm{v}$ $\mathrm{C}-\mathrm{OH}$ ), $1160 \mathrm{~cm}^{-1}$ (edge $\left.\mathrm{OH}\right), 1065 \mathrm{~cm}^{-1}$ (UC-O from-CoO- ), as well as the band at $3640 \mathrm{~cm}^{-}$ ${ }^{1}$ characteristic to isolated $-\mathrm{OH}$ groups and the doublet around $2800 \mathrm{~cm}^{-1}$ characteristic to methylene groups [23]. The spectrum of HT3Ce displayed a broad asymmetric absorption band in the region of hydroxyl groups with a maximum centered at $3597 \mathrm{~cm}^{-1}$, the bandspecific for interlayer water bending at 1653 $\mathrm{cm}^{-1}$, the one for carbonate ion vibration at 1435 $\mathrm{cm}^{-1}$, a broad asymmetric absorption band with the maximum at $946 \mathrm{~cm}^{-1}$ which is due to the overlapping of different vibration modes and a doublet of weak bands at 505 and $580 \mathrm{~cm}^{-1}$ characteristic to $\mathrm{Ce}-\mathrm{O}$ and $\mathrm{Al}-\mathrm{O}$ vibrations [24]. The spectra of the HT3Ce-xGO composites indirectly showed a perturbation of the $\mathrm{LDH}$ interlayer region under the influence of the GO component caused by noticeable vibrations of hydrogen bonds formed between water molecules and the anions located in the interlayer region (shoulder at $3450 \mathrm{~cm}^{-1}$ ) and the shifting of the band corresponding to $\mathrm{v}_{\mathrm{OH}}$ to higher wavelengths $\left(3625 \mathrm{~cm}^{-1}\right.$ compared to $3597 \mathrm{~cm}^{-1}$ in HT3Ce). The occurrence of the bands characteristic for edge $\mathrm{OH}$ found in $\mathrm{GO}$ at 1264 and $1160 \mathrm{~cm}^{-1}$ (which are more visible in the spectrum of HT3Ce-15GO) has indicated that a decrease in size of the particles found in the powder form is correlated with the increase of the content in GO component, thus confirming the observations from SEM analysis [25].

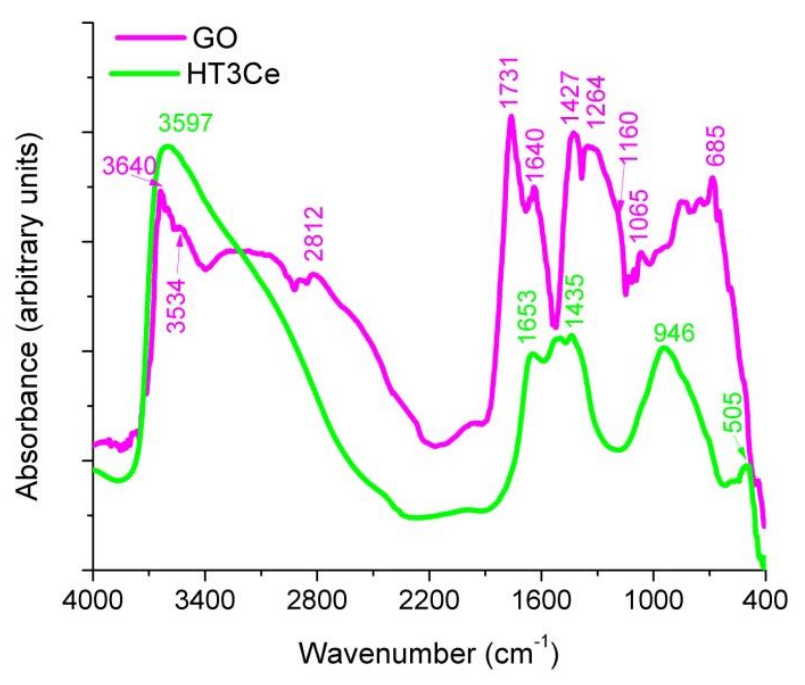

(a)

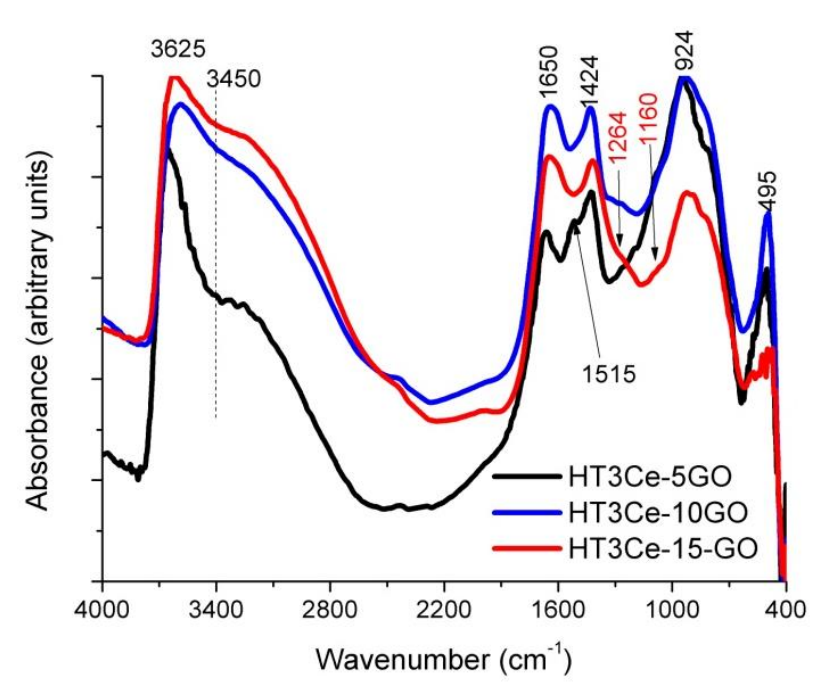

(b)

Fig. 5. DRIFT spectra of the freshly prepared solids (a) - GO and HT3Ce; (b) HT3Ce-xGO composites

The results of the catalytic tests performed in a batch system at room temperature using $1 \mathrm{wt} . \%$ catalyst in simulated wastewater containing 420 ppm indigo carmine (IC) and $\mathrm{H}_{2} \mathrm{O}_{2}$ (5.5 wt.\%) as the oxidation agent are displayed in Table 1 and Table 2.

The results in Table 1 highlight, without any doubt the activation effect of the ultrasonic irradiation which allowed doubling the DR\% in the first 30 minutes of reaction time and reaching after $2 \mathrm{~h}$ to the same DR\% as in the tests performed with LDH containing catalysts under continuous stirring for $4 \mathrm{~h}$. The results of the blank tests performed without any catalyst have indicated also the role played by US irradiation in $\mathrm{H}_{2} \mathrm{O}$ splitting into radicals which have increased the amount of oxidizing species in the reaction mixture [6]. Under both testing conditions, the composite catalysts HT3CexGO were more active than the neat components and their activity increased along with their GO content. This fact was well correlated to the structural analysis of the composites which showed their higher 
crystallinity compared to the neat components, as well as the beneficial effect of GO content increase on the distribution of the small-sized particles, which could lead to an enhancement of the catalytic activity due to better accessibility to the active sites.

Table 1. The extent of dye removal (DR\%) after the oxidation of IC with $\mathrm{H}_{2} \mathrm{O}_{2}$ in the tests performed under ultrasonic irradiation (UST) and under stirring (400 rot/min) (ST)

\begin{tabular}{|c|c|c|c|c|c|c|}
\hline Catalyst & HT3Ce & HT3Ce-5GO & HT3Ce-10GO & HT3Ce-15GO & GO & blank \\
\hline UST & & & & & & \\
\hline $30 \mathrm{~min}$ & 48.0 & 57.1 & 61.7 & 78.1 & 49.9 & 12.7 \\
\hline $1 \mathrm{~h}$ & 55.4 & 68.6 & 73.2 & 84.6 & 52.2 & 12.9 \\
\hline $2 \mathrm{~h}$ & 70.3 & 81.5 & 85.6 & 97.3 & 58.2 & 13.3 \\
\hline ST & & & & & & \\
\hline $30 \mathrm{~min}$ & 20.6 & 27.2 & 28.6 & 33.5 & 15.1 & 4.4 \\
\hline $1 \mathrm{~h}$ & 35.6 & 40.5 & 44.1 & 58.5 & 20.6 & 4.7 \\
\hline $2 \mathrm{~h}$ & 57.9 & 65.3 & 69.7 & 76.5 & 32.3 & 5.1 \\
\hline $3 \mathrm{~h}$ & 66.2 & 72.0 & 75.6 & 88.2 & 41.2 & 5.7 \\
\hline $4 \mathrm{~h}$ & 70.5 & 81.6 & 85.4 & 97.0 & 54.1 & 6 \\
\hline $5 \mathrm{~h}$ & 80.2 & 87.5 & 90.2 & 97.6 & 60.4 & 6.2 \\
\hline $6 \mathrm{~h}$ & 86.0 & 93.2 & 96.0 & 98.0 & 64.5 & 6.7 \\
\hline $24 \mathrm{~h}$ & 90.0 & 96.3 & 97.7 & 99.5 & 68.3 & 7.5 \\
\hline
\end{tabular}

Table 2. The values of COD and TOC after the oxidation of IC with $\mathrm{H}_{2} \mathrm{O}_{2}$ in the tests performed under ultrasonic irradiation (UST) for $2 \mathrm{~h}$ and under stirring (400 rot $/ \mathrm{min}$ ) (ST) for $4 \mathrm{~h}$, and $24 \mathrm{~h}$ (the initial values of COD and TOC were $574.7 \mathrm{mg} \mathrm{O} / \mathrm{L}$, and $174.2 \mathrm{mg} \mathrm{C} / \mathrm{L}$, respectively)

\begin{tabular}{|c|c|c|c|c|c|}
\hline Catalyst & HT3Ce & HT3Ce-5GO & HT3Ce-10GO & HT3Ce-15GO & $\mathrm{GO}$ \\
\hline UST $2 \mathrm{~h}$ & & & & & \\
\hline $\mathrm{COD}\left(\mathrm{mg} \mathrm{O}_{2} / \mathrm{L}\right)$ & 256 & 205 & 186 & 132 & 312 \\
\hline $\mathrm{COD}_{\text {decrease }}(\%)$ & 55.3 & 64.3 & 67.6 & 77 & 45.6 \\
\hline TOC (mg C/L) & 108 & 86 & 78 & 56 & 131 \\
\hline $\mathrm{TOC}_{\text {decrease }}(\%)$ & 37.5 & 50.0 & 54.6 & 67.7 & 23.9 \\
\hline ST $4 \mathrm{~h}$ & & & & & \\
\hline $\mathrm{COD}\left(\mathrm{mg} \mathrm{O}_{2} / \mathrm{L}\right)$ & 255.8 & 204.7 & 187.2 & 133.8 & 331.2 \\
\hline $\mathrm{COD}_{\text {decrease }}(\%)$ & 55.5 & 64.4 & 67.4 & 76.7 & 42.4 \\
\hline TOC (mg C/L) & 107 & 86 & 79 & 56 & 139 \\
\hline $\mathrm{TOC}_{\text {decrease }}(\%)$ & 37.7 & 50.0 & 54.4 & 67.4 & 19.3 \\
\hline ST $24 \mathrm{~h}$ & & & & & \\
\hline $\mathrm{COD}\left(\mathrm{mg} \mathrm{O}_{2} / \mathrm{L}\right)$ & 166 & 137 & 130.6 & 122.3 & 265.9 \\
\hline $\mathrm{COD}_{\text {decrease }}(\%)$ & 71.1 & 76.2 & 77.3 & 78.7 & 53.7 \\
\hline TOC (mg C/L) & 70 & 58 & 55 & 51 & 112 \\
\hline TOC $_{\text {decrease }}(\%)$ & 59.6 & 66.6 & 68.2 & 70.2 & 35.2 \\
\hline
\end{tabular}

For all the catalysts, the values of COD and TOC determined after the tests performed with ultrasonication for $2 \mathrm{~h}$, and after the tests performed under stirring for $4 \mathrm{~h}$ and $24 \mathrm{~h}$ are presented in Table 2.

For the most active catalyst, HT3Ce-15GO, the COD after 30 minutes reaction time under ultrasonic irradiation was $221 \mathrm{mg} \mathrm{O}_{2} / \mathrm{L}$, while TOC was $93 \mathrm{mg} \mathrm{C} / \mathrm{L}$ marking a decreased percentage of $61.6 \%$ for COD and $46.2 \%$ for TOC. The values of COD and TOC displayed in Table 2, showed that the total mineralization of the indigo carmine was not reached even when the dye removal exceeded $95 \%$. This fact was also noticed by other authors when they performed the photocatalytic oxidation on $\mathrm{TiO}_{2}$ [10]. However, the values obtained for COD using HT3Ce- $15 \mathrm{GO}$ were very close to the 
maximum admissible value for the direct discharge in water bodies of the treated wastewater sample (e.g. $125 \mathrm{mg} \mathrm{O}_{2} / \mathrm{L}$ ) [26]. For all the other catalysts, the treated wastewater fulfilled the requirements for discharge in a water treatment plant (e.g. COD $<500 \mathrm{mg}$ $\left.\mathrm{O}_{2} / \mathrm{L}\right)$ [27].

The DRIFT spectra of the catalysts recovered after the catalytic tests performed during $2 \mathrm{~h}$ under ultrasonic irradiation and after $24 \mathrm{~h}$ under stirring conditions are presented in Fig. 6.

The spectra of the composites used in UST (Fig. 6a) indicate that the ultrasonic radiation and the contact with the dye and $\mathrm{H}_{2} \mathrm{O}_{2}$ affected similarly all three composites, mainly by decreasing the intensity and the broadness of the bands located in the region $4000-3000 \mathrm{~cm}^{-1}$ where the vibrations characteristic to hydroxyl groups and interlayer interactions through hydrogen bonds appear. This fact correlated with the shifting of the band at 1650 to 1662 $\mathrm{cm}^{-1}$, and the appearance of two new bands at 1210 and $1111 \mathrm{~cm}^{-1}$ may be due to the incorporation of indigo carmine or some of its degradation products in the interlayer region of the solids. The spectra of the composites used in ST (Fig. 6b) show a similar effect in the midinfrared region accompanied also by a decrease of the intensity and the broadness of the bands in the region $4000-3000 \mathrm{~cm}^{-1}$, but this effect is more pronounced for the samples HT3Ce-5GO and HT3Ce-10GO. The spectrum of HT3Ce$15 \mathrm{GO}$ suggests that most probably because this solid had smaller particles, the incorporation of guest species in its interlayer region was more intense since the intensity of the band at 3270 $\mathrm{cm}^{-1}$ is twice as big compared to the other two composites.

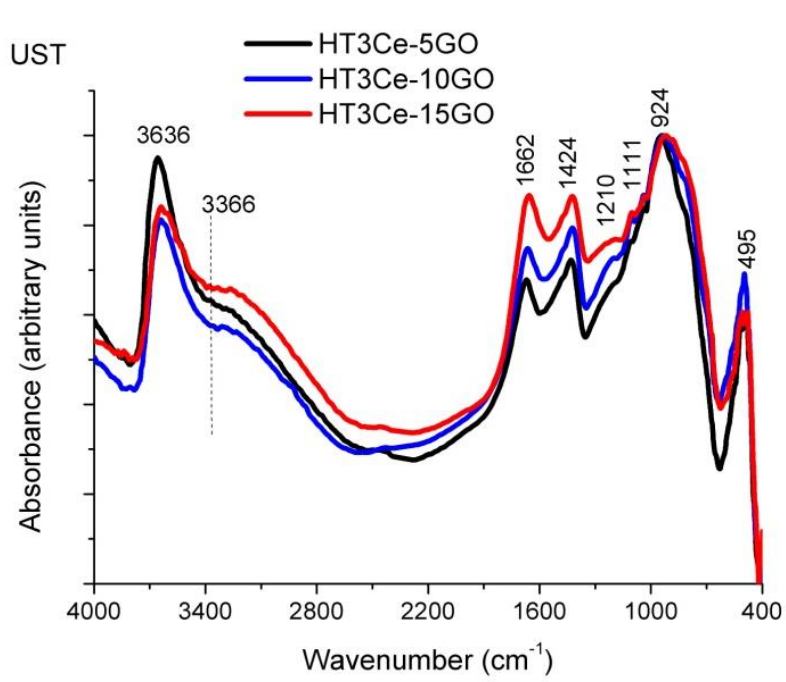

(a)

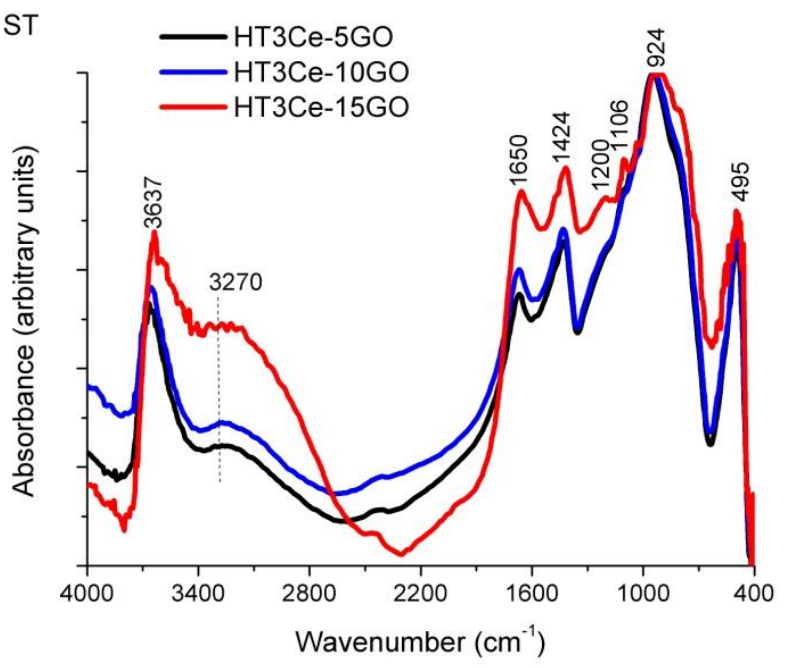

(b)

Fig. 6. DRIFT spectra of the spent HT3Ce-xGO composites: (a) after $2 \mathrm{~h}$ oxidation of IC under ultrasonic irradiation - UST; (b) after $24 \mathrm{~h}$ oxidation of IC under stirring (400 rot $/ \mathrm{min}$ ) - ST

\section{CONCLUSIONS}

Based on the above-presented results, it may be concluded that the co-precipitation of $\mathrm{Mg}_{3} \mathrm{Al}_{0.75} \mathrm{Ce}_{0.25} \mathrm{LDH}$ in the presence of $\mathrm{GO}$ suspension leads to HT3Ce-xGO composites with increased crystallinity of the LDH-phase compared to the synthesis of $\mathrm{Mg}_{3} \mathrm{Al}_{0.75} \mathrm{Ce}_{0.25}$ LDH using only aqueous solutions when the LDH phase was impurified with Cerium hydroxycarbonate and $\mathrm{CeO} 2$. This fact suggests that the presence of GO nanosheets with an increased number of defect sites on the surface, as it was indicated by the $\mathrm{I}_{\mathrm{D}} / \mathrm{I}_{\mathrm{G}}$ ratio of 1.316 determined by Raman spectroscopy, could both promote the in-situ formation and immobilization of LDH on GO, and inhibit the agglomeration of LDH nanosheets during the growth process while orientating the crystallization of the LDH phase. The XRD patterns of the composites indicated that besides the $\mathrm{CeO}_{2}$ phase there were no other impurities. Raman spectroscopy highlighted clearly the existence of $\mathrm{GO}$ in the HT3Ce-xGO composites. The appearance of $\mathrm{CeO}_{2}$ nanocrystallites in the structure of the composites played the main role in promoting the catalytic oxidation of indigo carmine with 
$\mathrm{H}_{2} \mathrm{O}_{2}$. Structural analyses indicated that the dimensions of the nanocomposite particles have decreased with the increase of GO content, thus leading to an enhanced dispersion of the catalytic active sites. The results of the catalytic tests for the oxidation of indigo carmine

\section{ACKNOWLEDGEMENTS}

This work was supported by a grant of the Romanian Ministry of Research and Innovation, CCCDI - UEFISCDI, project number PN-III-

\section{REFERENCES}

[1] NATARAJAN, S., BAJAJ, H. C., TAYADE, R. J., J. Environ. Sci., 65, 2018, p. 201.

[2] CHAN, S. H. S. WU, T. Y., JUAN, J. C., TEH, C. Y., J. Chem. Technol. Biotechnol., 86, 2011, p. 1130.

[3] POYATOS, J. M., MUÑIO, M. M., ALMECIJA, M. C., TORRES, J. C., HONTORIA, E., OSORIO, F., Water Air Soil Pollut., 205, 2010, p. 187.

[4] EREN, Z, J. Environ. Manage. 104, 2012, p. 127.

[5] MAHAMUNI, N. N. ADEWUYI, Y. G., Ultrason. Sonochem., 17, 2010, p. 990.

[6] ANANDAN, S., KUMAR PONNUSAMY, V., ASHOKKUMAR, M., Ultrason. Sonochem., $\quad$ 67, 2020, 105130, https://doi.org/10.1016/j.ultsonch.2020.105130. [7] KONIG, J., Colour Additives for Foods and Beverages, Woodhead Publishing, 2015, p. 35-60, https://doi.org/10.1016/C2013-016427-6.

[8] ARONSON J.K., Meyler's Side Effects of Drugs: The International Encyclopedia of Adverse Drug Reactions and Interactions, Sixteenth Edition, Elsevier Science, 2016, p. 433-436.

[9] JABS, C.F.I., DRUTZ, H.P., SUMMIT JR., R. I. Am. J. Obst. Gynecol. 185, 2001, p. 1368.

[10] VAUTIER, M., GUILLARD, C., HERRMANN, J.-M., J. Catal., 201, 2001, p. 46.

[11] VIDYA LEKSHMI, K. P., YESODHARAN, S., YESODHARAN, E. P. Heliyon 4, 2018, e00897, https://doi.org/10.1016/j.heliyon.2018.e00897. suggested a synergetic effect of GO and HT3Ce which led to increased catalytic activity, and its highest value was noticed for the composite HT3Ce-15GO, mostly under ultrasonic irradiation.

P1-1.2-PCCDI-2017-0387/80PCCDI Acronym EMERG2Ind, within PNCDIII.

[12] STARUKH H., LEVYTSKA S. Appl. Clay. Sci. 180, 2019, 105183, https://doi.org/10.1016/j.clay.2019.105183.

[13] CAVANI, F., TRIFIRO, F., VACCARI, A., Catal. Today, 11, 1991, p. 173.

[14] DREYER, D. R., JIA, H.-P., BIELAWSKI, C. W., Angew. Chem. Int. Ed., 49, no. 38, 2010, p. 6813.

[15] SAROYAN, H., KYZAS, G. Z., DELIYANNI, E. A., Processes, 7, 2019, 40, https://doi.org/10.3390/pr701004.

[16] HUMMERS, W.S., Jr., OFFEMAN, R.E., J. Am. Chem. Soc. 80, no. x, 1958, p. 1339.

[17] BIRJEGA, R., PAVEL, O.D., COSTENTIN, G., CHE, M., ANGELESCU, E., Appl. Catal. A: Gen., 208, 2005, p. 185.

[18] CHANNEI, D., NAKARUK, A., PHANICHPHANT, S., Mater. Lett. 209, 2017, p. 43.

[19] WANG, Q., GAO, Y., LUO, J., ZHONG, Z., BORGNA, A., GUO, Z., O'HARE, D., RSC Advances, 3, 2013, p. 3414.

[20] FROST, R. L., SCHOLZ, R., LÓPEZ, A., THEISS, F. L., Spectrochim. Acta A, 118, 2014, p. 187.

[21] SCHILLING, C., HOFMANN, A., HESS, C., GANDUGLIA-PIROVANO, M. V., J. Phys. Chem. C, 121, no. 38, 2017, p. 20834.

[22] CLARAMUNT, S., VAREA, A., LOPEZDIAZ, D., VELAZQUEZ, M. M., CORNET, A., CIRERA, A. J. Phys. Chem. C, 119, no. 18, 2015, p. 10123

[23] STANKOVICH, S. PINER, R. D., NGUYEN, S.B. T., RUOFF R. S., Carbon, 44, 2006, p. 3342.

[24] WANG, Z., FONGARLAND, P., LU, G., ESSAYEM, N., J. Catal., 318, 2014, p. 108. 
[25] SONG, Y.F., ZHANG, W., WANG, Z., [in Romanian].

ZHAO, Y., MIRAS, H. N., ChemCatChem, 11, [27] NTPA-002/2002 norms (updated in 2005) no. 22, 2019, p. 5466.

[26] NTPA-001/2002 norms (updated in 2007) regarding the admissible concentration of pollutants in industrial and domestic wastewaters for their discharge in natural receptors published in Monitorul Oficial, Part I no. 187 of 20.03.2002, updated in 19.03.2007 regarding the conditions for the discharge of wastewaters in the urban sewage system and directly into the water treatment plants, published in Monitorul Oficial, Part I no. 187 of 20.03.2002, updated in 11.05.2005 [in Romanian]. 